\title{
INDICADORES DE QUALIDADE PARA A AVALIA- ÇÃO DE TRADUÇÕES NO ÂMBITO DA DIDÁTICA
}

\author{
Radegundis Stolze*
}

\begin{abstract}
RESUMO: A avaliação de traduções visa medir a qualidade dos textos traduzidos. Contudo, o tradutor que tenta formular a tradução, o cliente que paga por ela e o professor de tradução que tem de avaliar o processo de aprendizagem têm perspectivas diferentes em relação à qualidade. A avaliação em sala de aula baseia-se na análise estática do texto, ao passo que o cliente tem um interesse prospectivo pelas traduções, já que sua intenção é usá-las funcionalmente a fim de atender seus próprios interesses. O tradutor, por sua parte, emprega uma estratégia dinâmica na busca de uma formulação adequada. Essas três perspectivas acerca da qualidade de traduções podem ser reunidas sob um modelo único das categorias tradutórias.
\end{abstract}

UNITERMOS: avaliação da qualidade; temática; léxico; pragmática; estilística.

A prática da tradução é a transferência de um texto previamente compreendido para outra língua. Essa atividade a serviço da comunicação intersubjetiva situa-se no interior de uma rede de múltiplas expectativas, todas convergindo para a competência tradutória. O tradutor moderno deve estar sempre pronto a concentrar-se em material textual novo e em áreas especializadas, assim como a refletir sobre suas próprias decisões e a conduzir seu trabalho de forma consciente. Do ponto de vista hermenêutico (ver Stolze 1997), o tradutor, como pessoa, é a instância central

(*) Universidade Técnica de Darmstadt

TradTerm, 4(1), $1^{\circ}$ semestre de 1997, p. 157-173 
da tradução. Seu cabedal de conhecimento e sua metodologia não podem ser ignorados como partes da competência tradutória. Nesse sentido, a tradução é vista de ângulos diversos.

A pedagogia da tradução tem como objetivo construir tal competência tradutória. Um recurso no ensino é a avaliação de traduções-testes, que passam a ser, então, objetos de análise. Posteriormente o tradutor profissional terá de avaliar suas próprias decisões tradutórias no decorrer do processo de tradução. Finalmente, o cliente, como "desencadeador" do processo e comprador de traduções vistas como produtos, realizará também sua avaliação antes de aceitá-las.

Em cada um desses casos, o objetivo é obter-se uma tradução "boa". Contudo, as perspectivas da avaliação são variáveis conforme os interesses particulares. Uma tradução adequada não é simplesmente um texto "utilizável", mas requer "que o tradutor objetive produzir um texto funcional na lingua de chegada que se adapte aos requisitos do skopos da tradução, tal como fixado pelo desencadeador, respeitando, ao mesmo tempo, caso necessário, tanto os legítimos interesses do autor do texto original, quanto o dos leitores da tradução" (Nord 1992: 40). Todavia, esses requisi-

Layout Corresponde o layout da tradução aos padrões estabelecidos, relativos à forma, à extensão, à completitude? (Temática, Pragmática)

Coerência A tradução é clara e inteligivel, livre de afirmações implausiveis e correta quanto à gramática e à ortografia? (TEMÁTICA)

Terminologia A terminologia é correta e consistente ao longo de todo o texto? (LÉxico)

Tipologia A tradução é utilizável segundo as normas estilís-

ticas da redação técnica, da linguagem jurídica, do estilo científico almejado, das regras de correspondência? (Pragmática, Estilística)

Estilo A tradução é de fácil leitura, fluente, livre de elementos estranhos? Está em conformidade com a identidade empresarial, com o estilo das partes do texto previamente redigidas? (EsTILÍsTICA) 
tos precisam ainda ser definidos. Considerando-se que a tradução é uma forma de comportamento lingüístico, tais requisitos podem ser descritos por categorias lingüísticas como TEMÁTICA, LÉXICO, PRAGMÁTICA E ESTILÍSTICA

O gerenciamento da qualidade na economia define qualidade como a satisfação ou aproximação de padrões específicos estabelecidos. O cliente profissional avaliará a tradução que lhe for apresentada de maneira prospectiva, de acordo com seus interesses, sem compará-la com o original. Alguns critérios freqüentemente empregados são:

No processo de tradução, o tradutor mantém-se dinamicamente à procura de uma formulação adequada. Numa abordagem holística, em vez de focalizar sobretudo um fato isolado, o/a tradutor(a) vê os problemas individuais segundo o papel por eles ocupado no interior de uma estratégia global. São três as questões que se costumam aplicar intuitivamente a um texto a ser traduzido:

Clareza Qual é a situação do texto (autor e contexto)? Entendi o texto completamente? Qual é sua estrutura essencial? O texto contém partes mal redigidas? Qual é seu status? Há divergência cultural relativa à cultura de chegada? (Temática, Pragmática)

Fidelidade Qual é a terminologia exata? Existe um campo lexical dominante no texto? Que marcadores formais são perceptíveis? Os números e os dados são precisos? (TEMÁTICA, LÉXICO)

Impacto A quem se destina a tradução? Que tipo de mudança é exigida pelas especificações daquele serviço? Quais são as qualidades estilísticas que desejo mostrar? Qual é a tipologia textual desejada para a tradução? Estou fazendo uso adequado dos recursos para a formação de palavras na linguagem técnica? (Pragmática, Estilística). 
A tarefa do ensino da tradução é fornecer uma base acadêmica para esses critérios um tanto gerais. A avaliação de testes de tradução, realizada no interior de uma estrutura pedagógica que leva em conta o nível de adiantamento, a apresentação do conhecimento, os objetivos do aprendizado etc., embora necessária, não é idêntica à avaliação feita por clientes ou tradutores profissionais. A tradução torna-se, na sala de aula, um objeto de análise. Como o ensino da tradução está muito freqüentemente aliado também ao aprendizado da língua, são necessárias uma análise objetiva de erros e uma terapia para sua prevenção. A avaliação de traduções se faz, na maior parte das vezes, como crítica à tradução, por meio da comparação entre a tradução e o texto original. Uma crítica da tradução que se baseie na equivalência será sempre estática (ver Reiß/Vermeer 1984: 139). A classificação dos erros, necessária para a atribuição de notas, continua sendo um ponto polêmico. Gostaria de sugerir uma lista simples de tipos de erros:

Gr - transgressão da ortografia, gramática e sintaxe da língua de chegada, provavelmente devido a interferência lingüística;

Se - $\quad$ sentido incorreto, entendido como desvio semântico do original motivado pela falta de conhecimento/entendimento de uma palavra, omissão de partes importantes do texto, uso incorreto de um termo especializado, números incorretos devidos freqüentemente a deslizes (Temática, LéXICO);

Ic - trecho incompreensivel, falta de coerência, idéias confusas (TEMÁtica);

Ex - falha de expressão causada por desconsideração do destinatário, inadequação à cultura de chegada (PRAGMÁTI$\mathrm{CA})$;

Tt - transgressão de normas específicas relacionadas à tipologia textual, registro estilístico impróprio (EsTILÍsTICA). 
As várias perspectivas em relação à qualidade e a avaliação que os clientes, tradutores e professores dela fazem levantam a questão acerca da possibilidade de integração, em um único modelo, de seus aspectos prospectivos, dinâmicos e estáticos, pois seria desejável que o aluno adquirisse uma compreensão da estrutura do processo tradutório em toda sua complexidade.

Os requisitos de qualidade para uma tradução - na visão do leitor, um texto independente; na do tradutor, uma tarefa a realizar e, na do professor, um objeto de crítica - podem ser explicados pelas categorias tradutórias: TEMÁTICA, LÉXICO, PRAGMÁTICA E ESTILÍsTica (ver Stolze 1992: 98).

Temática. Enquanto o cliente requer coerência na forma textual e na estrutura lógica, a didática da tradução pode apresentar essa categoria sob o tópico "fatores internos e externos na compreensão do texto". Neste último caso, haverá uma extensa análise do texto de partida em relação ao local de publicação, ao autor e a aspectos referentes ao veículo e ao layout.

Ao ler um texto com o intuito de entendê-lo, o estudante de tradução aprende a identificar sua estrutura temática por meio do contexto, da perspectiva do enunciador, da progressão temática, dos marcadores de transição entre parágrafos etc. Ele ou ela procurará indagar-se quanto ao status do texto, se técnico, pragmático ou literário, de acordo com a escala flexível de Snell-Hornby $(1988,115)$. A definição do gênero do texto pode dar uma indicação geral da sua estrutura e determinar todos os procedimentos posteriores.

A chave para que o tradutor entenda o texto encontra-se com freqüência em idéias centrais que constituem a linha isotópica e a rede semântica do texto. Por um lado, o tema é indicado pela recorrência de sinônimos; por outro, tal campo lexical já representa a estrutura básica do texto de chegada. O leitor espera coerência, no sentido de plausibilidade. Com certa freqüência, podemos observar que traduções são seletivamente equivalentes, mas carecem de uma coerência global no que diz respeito aos campos lexicais. 
A didática é capaz de evidenciar esse fato por meio da análise semântica. Nesse caso, a função do signo lingüístico será discutida em sua relação com a denotação no interior dos sistemas lingüísticos, com as conotações que adquire nas diferentes culturas e com as associações realizadas no processo individual de compreensão. Assim, constituem questões centrais: o sentido exato das palavras, o conhecimento das equivalências e a compatibilidade semântica e fraseológica. Tal processo é capaz de evidenciar uma série de erros. Diferentemente da abordagem holística do tradutor profissional, a didática da tradução concentra-se sobretudo em elementos textuais isolados, em seus campos de significação.

LÉxico. A categoria Léxico diz respeito à comunicação em áreas especializadas. O cliente profissional normalmente verificará, a partir de seu ponto de vista, a consistência terminológica relativa ao domínio de especialidade e à praxe terminológica vigente em sua própria empresa. Qualquer variação no uso dos termos poderia levar a desvios de compreensão da tradução.

A didática da tradução deve destacar os diferentes modos de terminologização, bem como os aspectos sintáticos da linguagem para fins específicos, de tal forma que o tradutor seja sensibilizado para as diferenças terminológicas e de constituição textual entre a área científica e a de humanidades.

Nas áreas das ciências técnicas e naturais, a terminologia atende ao progresso da ciência e à descrição dos objetos. A terminologia contem termos de definição exata, fixada em um sistema conceitual fechado. Ao longo do desenvolvimento científico, a quantidade de termos cresce constantemente, o que exige padronização e registro em bancos de dados. As diferenças e lacunas são detectadas por meio de comparação entre sistemas terminológicos em um par de línguas. Os sinônimos constituem um problema especial, freqüentemente causado por pontos de vista cientificos diferentes e coexistentes.

Nas áreas de humanidades e ciências sociais, por outro lado, a terminologia especializada está aberta a interpretações. Descreve sentimentos e idéias de pessoas, bem como procedimentos e processos da vida. As definições, entendidas como o 
conteúdo dos conceitos, são estabelecidas convencionalmente entre os autores em seu discurso acadêmico. Com freqüência permanecem objeto de disputa. Por isso, um autor normalmente define seus termos antes de prosseguir com sua exposição. Toda a idéia ou asserção só poderá ser compreendida adequadamente contra o pano de fundo da filosofia relevante.

Essa linguagem específica volta-se antes para a interpretação da vida e do pensamento das pessoas do que para a interpretação de objetos extralinguísticos. Por conseguinte, as palavras estão mais próximas da linguagem comum. Na maior parte das vezes, uma mudança de significado leva à redefinição ou à reinterpretação de um conceito já existente. O principal problema de tradução que surge daí é a necessidade de reconhecer tais termos especializados no interior de um texto que, à primeira vista, parecia usar linguagem comum com significado comum. Isso aplica-se também a textos jurídicos, onde um grande número de termos são palavras da linguagem comum que adquirem um significado especial. Os nomes de instituições não podem ser transferidos para o sistema jurídico da cultura de chegada, pois isso sugeriria identidade entre instituições, a qual não existe.

Pragmática. A categoria Pragmática refere-se ao público-alvo na cultura de chegada. O cliente interessado em atingir seus objetivos de negócios ou o leitor interessado em ler uma carta, um romance ou outra obra semelhante exigem simplesmente que a tradução seja funcionalmente adequada. Ele ou ela rejeitará todo e qualquer texto que não atenda a suas expectativas, ou que, na melhor das hipóteses, considerem "estranho". "A tradução [de textos de especialidade] não pode ser destoante ou estranha se comparada ao que seria normal para textos de chegada autênticos do mesmo tipo." (Nielsen, 1994, p. 25)

A didática deve discutir sistematicamente as possibilidades de abordagem das diferenças culturais. Isso pode ser realizado por meio do desenvolvimento de um a consciência acerca de incongruências culturais, do exercício de socioletos específicos na língua de chegada e da discussão de problemas de tradução no par de línguas em questão. Nesse caso, a análise estática 
focalizará tipos diversos de erros, como os falsos-cognatos, a polissemia no nivel da palavra e as diferenças sintáticas.

O tradutor, em sua busca dinâmica por uma formulação adequada, levará em consideração o skopos da tradução, isto é, as especificações de sua tarefa e a finalidade que se pretende que a tradução cumpra na cultura de chegada. A forma da comunicação - comunicação especializada interna entre acadêmicos; ou comunicação externa com o público, no sentido de transferência de conhecimentos - exige diferentes modos de formulação. O tradutor que prevê obstáculos à compreensão de seu leitor empregará estratégias de compensação, explicando, parafraseando, simplificando ou modificando o elemento textual de origem. (ver Stolze, 1992, p. 207)

O tradutor respeitará também os socioletos da língua de chegada, isto é, a linguagem própria de grupos específicos, tais como agências de fomento, igrejas, partidos politicos, o linguajar próprio de uma empresa etc. A pertinência a um dado grupo de usuários da língua se evidencia no jargão profissional e no linguajar ideológico. A fim de que a aceitabilidade de uma tradução esteja assegurada, é muito importante que se levem em conta tais preferências e normas discursivas, independentemente das que são válidas para o texto na língua de partida. A "abordagem funcional da tradução", tal como defendida por Vermeer, é comumente ilustrada pela transformação do linguajar clássico e exuberante do português em um linguajar mais neutro e funcional, típico de textos acadêmicos em alemão. (ver Wolf, 1997, p. 11)

Estilística. Todo significado é veiculado por meio de palavras, mas tradução é mais do que transcodificação verbal. A categoria Estilística concentra-se na formulação propriamente dita, como fenômeno retórico. O estilo não é uma mera decoração; é a maneira apropriada de expressar-se a si mesmo em uma determinada situação. Mesmo que o cliente espere da tradução tão-somente correção gramatical e sintática, facilidade de leitura e fluência do estilo, constitui tarefa da didática a criação de um conhecimento metalingüístico de elementos estilísticos, de convenções relativas à tipologia textual e de jargões funcionais. A 
formação de termos técnicos por composição, por extensão sintagmática, afixação etc., assim como as diferenças características entre as línguas devem ser discutidas, posto que constituem fonte de erros para a tradução.

Tendo em vista que, por exemplo, a sintaxe própria de textos científicos ou o estilo administrativo divergem entre as várias comunidades lingüísticas, o ensino da tradução deveria concentrar-se particularmente nesse ponto. Enquanto textos técnicos tendem a estruturas claras e lineares a fim de possibilitar sua compreensão, podemos observar que os textos de humanidades, com seu conteúdo argumentativo, freqüentemente lançam mão de um número maior de sinais de coesão a fim de balizar sua compreensão.

Nesse sentido, será necessário analisar os padrões relativos à tipologia textual e aos jargões funcionais da língua de chegada, tais como estilo nominal, voz passiva e atributos. A redação técnica é hoje objeto de pesquisa específica e de criação de normas de escrita. Em certos textos, podem ser identificadas macroestruturas específicas e fragmentos textuais fixos (ver Göpferich, 1995, pp. 217, 389). Esses estilos funcionais constituem uma seleção convencional feita a partir do potencial que a língua oferece.

É somente na literatura que a riqueza expressiva de uma lingua se realiza integralmente. Na literatura, a criatividade dos autores, expressa em formulações sintáticas incomuns ou em metáforas originais, deve encontrar sua contrapartida no trabalho do tradutor. Por essa razão, faz parte integrante das tarefas da didática da tradução na categoria da Estilística, apresentar métodos de criação de metáforas e suas imagens, tratar do papel estilístico desempenhado por palavras estrangeiras no alemão, dos aspectos sonoros, rítmicos além de outros elementos de estilo. Textos publicitários e jornalísticos requerem uma linguagem expressiva particular.

As categorias tradutórias se interrelacionam e são perceptiveis, em maior ou menor grau, em todo e qualquer texto. Sua aplicação só se torna possivel se considerarmos tanto o texto quanto a tradução como um todo. A proficiência lingüística e o 
conhecimento do assunto são precondições para a tradução e, portanto, não recebem menção especial aqui.

Em se tratando da questão da avaliação em tradução, devese ter em mente que as perspectivas que o cliente, o professor de tradução e o próprio tradutor adotam em relação à qualidade são diferentes entre si. O tradutor profissional pode se apoiar nas categorias tradutórias para defender suas decisões de eventuais críticas. O professor de tradução pode encontrar nelas um levantamento sistemático de todos os problemas lingüísticos normalmente discutidos em sala de aula. O "usuário" das traduções, por sua vez, encontrará nas categorias tradutórias uma descrição mais científica de seus próprios padrões de qualidade.

A conscientização quanto às diferentes perspectivas e a sua integração holística poderiam aprimorar nosso entendimento do processo de tradução no seu todo. Tal conscientização ao menos justifica a discussão de aspectos lingüísticos no ensino da tradução, desde que esses fenômenos lingüísticos não sejam tratados isoladamente, mas como partes importantes do processo de tradução em toda sua complexidade. 


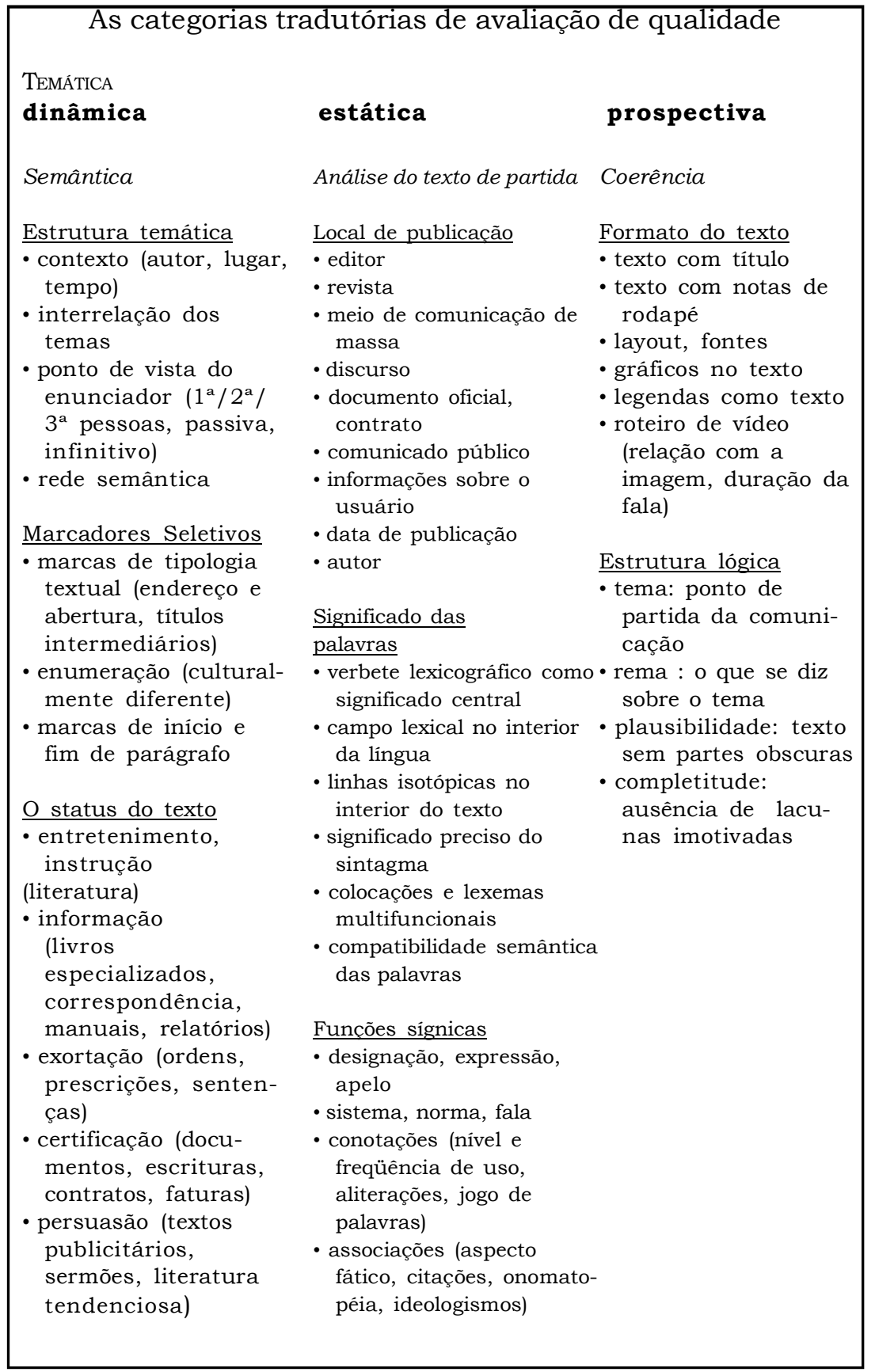

TradTerm, 4(1), $1^{\circ}$ semestre de 1997, p. 157-173 


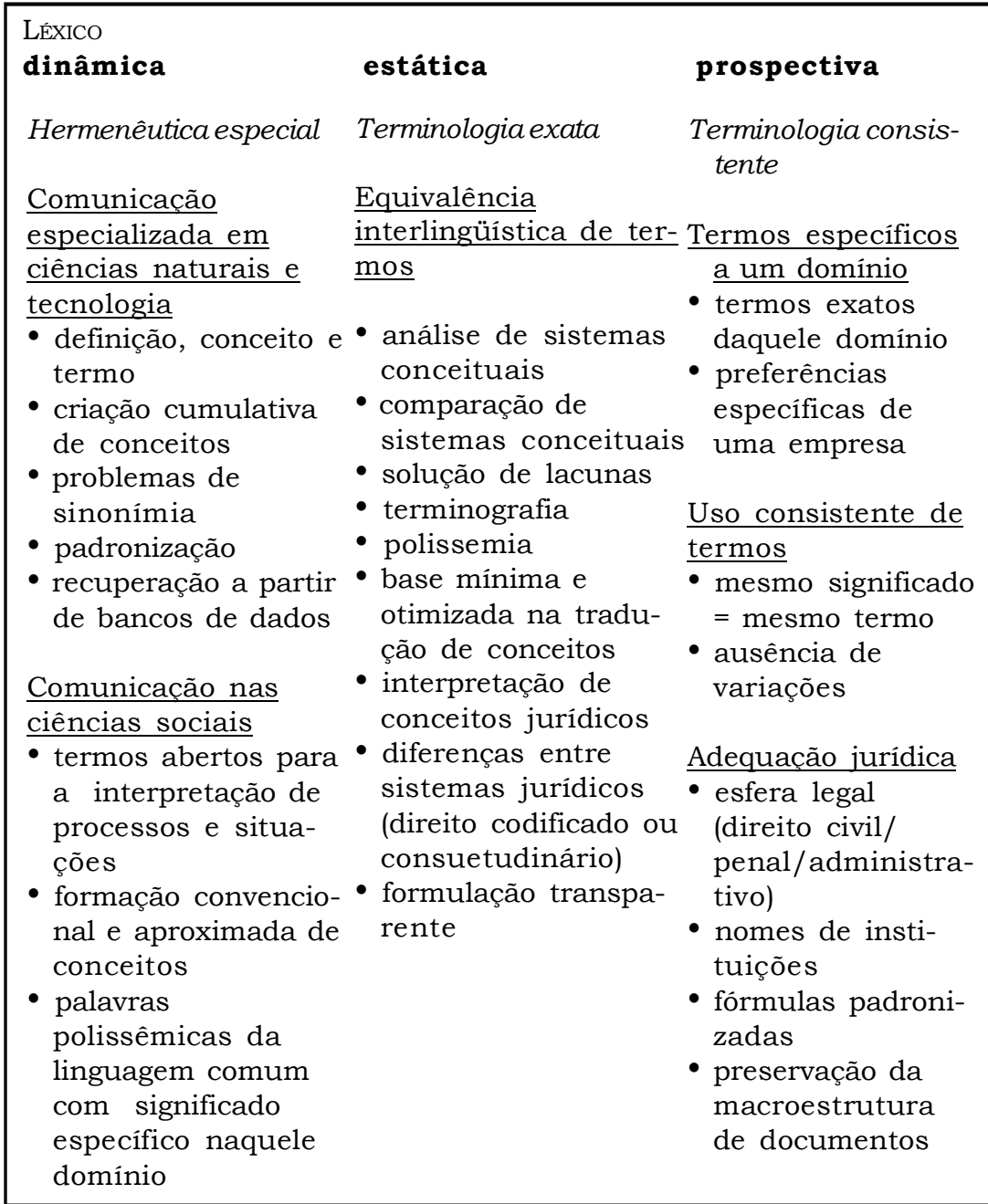




\begin{tabular}{|c|c|c|}
\hline $\begin{array}{l}\text { PRAGMÁTICA } \\
\text { dinâmica }\end{array}$ & estática & prospectiva \\
\hline $\begin{array}{l}\text { A função do texto e os } \\
\text { receptores }\end{array}$ & $\begin{array}{l}\text { Abordagem das } \\
\text { diferenças culturais }\end{array}$ & Adequação funcional \\
\hline 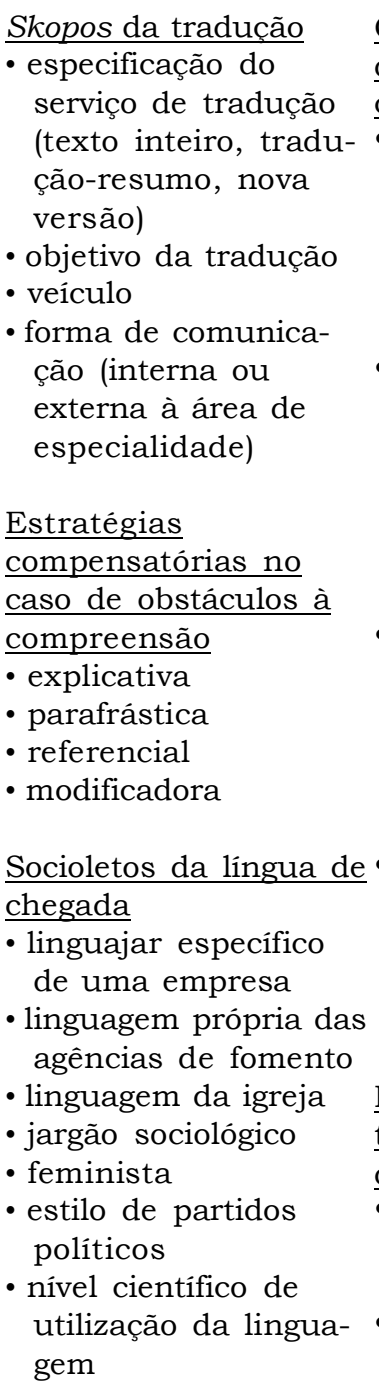 & $\begin{array}{l}\text { Consciência das } \\
\text { diferenças } \\
\text { culturais } \\
\text { incongruência real } \\
\text { (objetos desconhe- } \\
\text { cidos e peculiarida- } \\
\text { des da cultura de } \\
\text { partida, normas } \\
\text { técnicas nacionais) } \\
\text { - incongruência } \\
\text { formal (estruturas } \\
\text { de texto cultural- } \\
\text { mente especificas, } \\
\text { formas de trata- } \\
\text { mento, indicação de } \\
\text { datas, títulos etc.) } \\
\text { incongruência } \\
\text { semântica (diferen- } \\
\text { tes conotações de } \\
\text { uma palavra, } \\
\text { sistema de valores, } \\
\text { estereótipos) } \\
\text { incongruência } \\
\text { estilistica (estilos } \\
\text { de escrita nacio- } \\
\text { nais e máximas } \\
\text { discursivas) } \\
\text { Problemas de } \\
\text { tradução especificos } \\
\text { de um par de linguas } \\
\text { interferência } \\
\text { motivada por falsos } \\
\text { cognatos } \\
\text { diferenças de } \\
\text { processos de }\end{array}$ & $\begin{array}{l}\text { Função do texto } \\
\text { - transmitir } \\
\text { informação, fazer } \\
\text { um relato } \\
\text { - documento } \\
\text { - manual de } \\
\text { instruções } \\
\text { - propaganda } \\
\text { - aviso } \\
\text { - texto falado } \\
\text { - literatura } \\
\text { Linguagem } \\
\text { adequada ao grupo } \\
\text { - identidade } \\
\text { empresarial } \\
\text { - linguagem da } \\
\text { instituição } \\
\text { - estilo e forma } \\
\text { comercial } \\
\text { - formulação } \\
\text { orientada para o } \\
\text { receptor }\end{array}$ \\
\hline
\end{tabular}




\section{Tradução de documen- composição}

tos

- polissemia nas

- manter a estrutura do linguas românicas texto original

- precisão das

- identidade de forma palavras do alemão

- regras legais e do inglês

- autenticação da

- discurso indireto e tradução a seqüência de tempos

Textos publicitários

- foco no inglês e

- especificidade cultural alemão (inversão,

- atualidade (relação cisão, partículas, com o espírito de verbos conversos) época)

- diferenças quanti-

- personalização (tratamento pessoal) tativas no uso do

- afirmação do caráter artigo positivo

- sintagmas nominais abstratos

- linguagem expressiva

- palavras vazias (estilo fácil)

Textos literários

- ausência de objetivo

- especificidade cultural e visão de mundo subjetiva

- caráter ficcional

- estética literária e criatividade lingüística

- abertura para a criação e interpretação visionárias 


\begin{tabular}{|c|c|c|}
\hline $\begin{array}{l}\text { EsTILÍSTICA } \\
\text { dinâmica }\end{array}$ & estática & prospectiva \\
\hline $\begin{array}{l}\text { Convenções de gênero } \\
\text { textual e estilo funcional }\end{array}$ & Análise do estilo & $\begin{array}{l}\text { Idiomaticidade e } \\
\text { compreensibilidade }\end{array}$ \\
\hline $\begin{array}{l}\text { Normas esperadas } \\
\text { para uma dada } \\
\text { tipologia textual } \\
\text { - manual de instru- } \\
\text { ções } \\
\text { - informação médica } \\
\text { - manual eletrônico } \\
\text { - manual para a } \\
\text { oficina mecânica } \\
\text { - receitas culinárias } \\
\text { - artigo especializado } \\
\text { - relatório de confe- } \\
\text { rência } \\
\text { - carta comercial } \\
\text { - artigos de associa- } \\
\text { ções } \\
\text { - contrato de compra e } \\
\text { venda } \\
\text { - noticias sobre } \\
\text { mercado de ações } \\
\text { - texto de patente } \\
\text { - sentença judicial } \\
\text { - carta de referência } \\
\text { - certificado escolar } \\
\text { (texto internacional } \\
\text { da União Européia) } \\
\text { etc. } \\
\text { Linguagem dos meios } \\
\text { de comunicação de } \\
\text { massa e textos } \\
\text { - tornalísticos } \\
\text { - recursos expressivos } \\
\text { de linguagem (adjeti- } \\
\text { vos, ditos popula- } \\
\text { res, metáforas) } \\
\text { em alemão }\end{array}$ & $\begin{array}{l}\text { Análise de estilo } \\
\text { - estilo como escolha } \\
\text { do autor a partir do } \\
\text { potencial da língua } \\
\text { - o estilo é o que o } \\
\text { leitor vê } \\
\text { - análise macro e } \\
\text { microestilística } \\
\text { - estilística como } \\
\text { coleção de recursos } \\
\text { retóricos } \\
\text { - características de } \\
\text { época } \\
\text { - metáfora } \\
\text { - idioleto como traço } \\
\text { estilístico individu- } \\
\text { al } \\
\text { - socioleto como } \\
\text { linguagem de grupo } \\
\text { desvio artístico da } \\
\text { norma e linguagem } \\
\text { expressiva } \\
\text { Sintaxe da linguagem } \\
\text { especializada } \\
\text { - economia na } \\
\text { expressão e frases } \\
\text { simples } \\
\text { - construções nomi- } \\
\text { nais, locuções } \\
\text { formadas por } \\
\text { verbos funcionais } \\
\text { (sem significado) e } \\
\text { substantivos } \\
\text { discurso impessoal } \\
\text { (1a e } 3^{a} \text { pessoa do } \\
\text { singular/plural) }\end{array}$ & $\begin{array}{l}\text { Idiomaticidade } \\
\text { - ortografia } \\
\text { - correção gramati- } \\
\text { cal } \\
\text { - sintaxe } \\
\text { Compreensibilidade } \\
\text { - estrutura textual } \\
\text { clara } \\
\text { - nivel de estilo } \\
\text { correto } \\
\text { - estilo fluente } \\
\text { Especificidades } \\
\text { relativas à tipologia } \\
\text { textual } \\
\text { - macroestrutura } \\
\text { típica } \\
\text { - fragmentos } \\
\text { textuais tipica- } \\
\text { mente fixos }\end{array}$ \\
\hline
\end{tabular}


- aliteração, jogos de palavras e palavras artificiais

Textos técnicos

- ordem temática clara e sem inversões ou reversões

- ausência de lacunas lógicas no texto

- seqüência cronológica da ação expressa por meio da perspectiva da frase

- formação de palavras técnicas

- consistência

terminológica

- fórmulas sintáticas

- linguagem própria para instruções

- relação entre texto e imagem

O estilo funcional

alemão da

administração

- classificação por deverbais

- maior número de acusativos do que dativos

- expressão impessoal e generalizante

- descrição da ação na voz passiva

- ordens por meio de infinitivos com "seinzu"

- compressão da frase por meio de adjetivos compostos ou sufixados

- precisão excessiva na construção de orações complexas
- ausência de tempo passado

- prioridade para a construção passiva

- indicadores de ilocuçao (verbos performativos, palavras modais)

- diferenças entre linguas

Formação de palavras técnicas

- palavras compostas

- extensão sintagmática

- adjunto adjetivo relativo

- derivação

- abreviação

- afixos gregos e latinos

- fraseologia

- terminologização de palavras da linguagem comum

TradTerm, 4(1), $1^{\circ}$ semestre de 1997 , p. 157-173 


\section{Referências Bibliográficas}

GÖPFERICH, S. (1995) Textsorten in Naturwissenschaft und Technik. Tübingen, Narr.

NIELSEN, J. N. (1994) Professions, specific purpose languages and professional texts. Elements of the professional translator's knowledge. In: OFT Symposium Copenhagen Business School 11-12 April 1994 'Translating LSP texts', conference papers. Copenhagen, CBS, pp. 15-39.

NORD, C . (1992) Text analysis in translator training. In: DOLLERUP, C. and LINDEGAARD, A. (ed.) Teaching translation and interpreting. Training, talent and experience. Amsterdam/Philadelphia, Benjamin's Publishing, pp. 39-48.

REISS, K. e VERMEER, H. J. (1984) Grundlegung einer allgemeinen Translationstheorie. Tübingen, Niemeyer.

SNELL-HORNBY, M. (1988) Translation studies - An integrated approach. Amsterdam/Philadelphia, Benjamin's Publishing.

STOLZE, R. (1992) Hermeneutisches Übersetzen. Linguistische Kategorien des Verstehens und Formulierens beim Übersetzen. Tübingen, Narr.

STOLZE, R. (1997) The hermeneutic approach in translation. In: Translation studies in Germany, LÖRSCHER, W. (ed.) Número especial da Tha do Desterro 1997 (em preparação).

WOLF, M. (ed.) (1997) Übersetzungswissenschaft in Brasilien. Beiträge zum Status von "Original" und Übersetzung. Mit einem Vorwort von Hans J. Vermeer. Tübingen, Stauffenburg. 